\title{
Interleukin-32 in systemic sclerosis, a potential new biomarker for pulmonary arterial hypertension
}

Paola Di Benedetto ${ }^{1 \dagger}$, Giuliana Guggino ${ }^{2 \dagger}$, Giovanna Manzi ${ }^{3}$, Piero Ruscitti ${ }^{4}$, Onorina Berardicurti ${ }^{4}$, Noemi Panzera $^{1}$, Nicolò Grazia ${ }^{1}$, Roberto Badagliacca ${ }^{3}$, Valeria Riccieri ${ }^{5}$, Carmine Dario Vizza ${ }^{3}$, Ganna Radchenko ${ }^{6}$, Vasiliki Liakouli' Francesco Ciccia ${ }^{7}$, Paola Cipriani ${ }^{4+}$ and Roberto Giacomelli ${ }^{4 *}{ }^{*}$ (D)

\begin{abstract}
Background: Pulmonary arterial hypertension (PAH) is a severe complication of systemic sclerosis (SSC), associated with a progressive elevation in pulmonary vascular resistance and subsequent right heart failure and death. Due to unspecific symptoms, the diagnosis of PAH is often delayed. On this basis, it is of great value to improve current diagnostic methods and develop new strategies for evaluating patients with suspected PAH. Interleukin-32 (IL-32) is a proinflammatory cytokine expressed in damaged vascular cells, and the present study aimed to assess if this cytokine could be a new biomarker of PAH during SSc.
\end{abstract}

Methods: The IL-32 expression was evaluated in the sera and skin samples of 18 SSc-PAH patients, 21 SSc patients without PAH, 15 patients with idiopathic PAH (iPAH) and 14 healthy controls (HCS), by enzyme-linked immunosorbent assay (ELISA) and immunohistochemistry (IHC). Receiver-operating characteristic (ROC) curves were performed to evaluate the cut-off of IL-32 in identifying patients with PAH. Furthermore, in SSc patients, correlation analyses were performed between IL-32 sera levels and mean pulmonary artery pressure (mPAP) evaluated by right heart catheterization (RHC) and systolic pulmonary artery pressure (sPAP), obtained by echocardiography. Additionally, the number of skin IL-32+ cells was correlated with modified Rodnan skin score (mRSS).

Results: In SSc-PAH patients, IL-32 sera levels were significantly higher when compared with SSc patients without PAH and patients affected by $\mathrm{PAH}$. The analysis of ROC curve showed that IL-32 sera levels above $11.12 \mathrm{pg} / \mathrm{ml}$ were able to predict patients with PAH (sensitivity $=90 \%$, specificity $=100 \%$ ). Furthermore, the IL-32 sera levels of patients with SSC correlated with both mPAP and SPAP. In the skin derived from SSC-PAH patients, the number of IL-32+ cells was significantly increased when compared with the skin derived from SSC patients without PAH, correlating with the mRSS.

Conclusion: Our study suggested that sera determination of IL-32 may be a promising approach to evaluate the presence of PAH in SSC patients and together with longitudinal future studies could help to increase the understanding how these biomarkers mirror the vascular changes and the inflammatory process during SSc.

Keywords: Systemic sclerosis, Pulmonary arterial hypertension, IL-32

* Correspondence: roberto.giacomelli@cc.univaq.it

†Paola Di Benedetto, Giuliana Guggino, Paola Cipriani and Roberto Giacomelli contributed equally to this work.

${ }^{4}$ Division of Rheumatology, Department of Biotechnological and Applied Clinical Sciences, University of L'Aquila, L'Aquila, Italy

Full list of author information is available at the end of the article

(c) The Author(s). 2020 Open Access This article is licensed under a Creative Commons Attribution 4.0 International License, which permits use, sharing, adaptation, distribution and reproduction in any medium or format, as long as you give appropriate credit to the original author(s) and the source, provide a link to the Creative Commons licence, and indicate if changes were made. The images or other third party material in this article are included in the article's Creative Commons licence, unless indicated otherwise in a credit line to the material. If material is not included in the article's Creative Commons licence and your intended use is not permitted by statutory regulation or exceeds the permitted use, you will need to obtain permission directly from the copyright holder. To view a copy of this licence, visit http://creativecommons.org/licenses/by/4.0/ The Creative Commons Public Domain Dedication waiver (http://creativecommons.org/publicdomain/zero/1.0/) applies to the data made available in this article, unless otherwise stated in a credit line to the data. 


\section{Background}

Systemic sclerosis (SSc) is a systemic autoimmune disease characterised by microvascular damage and progressive fibrotic manifestations of the skin and internal organs [1-4], classified in two different subsets, displaying different clinical patterns and outcomes: limited cutaneous (lcSSc) and diffuse cutaneous (dcSSc). Cardiopulmonary involvement is the most common cause of morbidity and mortality in those patients [5]. According to the last clinical classification of pulmonary arterial hypertension $(\mathrm{PAH})$, pulmonary hypertension can occur due to pure vascular involvement (WHO Group 1), secondary to SSc-interstitial lung disease (WHO Group 2) and secondary to cardiac involvement (post-capillary pulmonary hypertension, WHO Group 3) in those patients [6]. Isolated PAH (in the absence of lung fibrosis) is one of the more severe complications of SSc, associated with a very high mortality rate, [7]. It has been reported that the 1-year survival rates for SSc-PAH patients range from 50 to $81 \%$ [8], having about a threefold increase in the mortality risk when compared with iPAH [9]. Thus, an early diagnosis is essential, because the late referral to cardiologists, when the symptoms of right heart dysfunction are already present, predicts a worse survival $[10,11]$. However, early and accurate diagnosis of $\mathrm{PAH}$ is a clinical challenge, needing right heart catheterization (RHC), an invasive test which have to be performed in those patients at increased risk of $\mathrm{PAH}$, following echocardiographic results and additional criteria [12-14]. In this context, the availability of suitable diagnostic biomarkers for an early identification of SSc-PAH patients, still in asymptomatic phase, may significantly impact patient's survival. A large number of circulating biomarkers have been investigated in the last years, but so far, only B-type natriuretic peptide (BNP) and N-terminal proBNP (NT-proBNP) are routinely used in the clinical setting, since being associated with the severity of heart involvement $[15,16]$.

It is well known that pulmonary arteries display complex structural and functional changes during $\mathrm{PAH}$ and pulmonary endothelial cells' (ECs) dysfunction plays a crucial role in disease progression, leading to vascular defects observed in SSc patients [17-22]. Hyperproliferative ECs may contribute to pulmonary arterial remodelling, leading to the obliteration of vascular lumen [23]. IL-32, a proinflammatory cytokine, originally described as a transcript termed NK4, is considered a key regulator molecule of EC activities [24, 25]. Although 9 different isoforms are described according to varying mRNA splicing [26], IL-32 $\alpha$, IL32- $\beta$ and IL-32 $\gamma$ are the most prominent isoforms [24]. Biologically, IL-32 resembles the activity of another cytokine of the same family, the IL-33 [27], largely activated in damaged ECs of SSc [28] and over-expressed in arteries of giant cell arteritis patients [29, 30], acting as a "danger signal/alarmin" molecule. The EC production of IL-32 is enhanced by various inflammatory stimuli, such as IL-1b, IL-1a, IL-6, and IL-8, and among them IL- 1 and IL-8 are potent promoters of angiogenesis [24, 31]. Of interest, IL32 has been identified in the abnormal ECs, populating the plexiform lesions in the lungs of patients with $\mathrm{iPAH}$ [25], and probably involved in both activation and proliferation of these ECs. Increased IL-32 levels have been found associated with $[25,32,33]$ activity and/or severity of Behcet's disease [34], systemic lupus erythematosus and atopic dermatitis [35, 36]. Presently, the role of IL32 in SSc is still unknown; thus, we assessed the expression of IL-32 in the sera of SSc patients with PAH (WHO Group 1) and compared these values with those from SSc patients without $\mathrm{PH}$ and patients with iPAH. In addition, we correlated the IL-32 sera levels with the mean pulmonary artery pressure (mPAP) assessed by RHC and the values of systolic pulmonary artery pressure (sPAP), obtained by echocardiography, to understand if IL-32 may be considered an additional non-invasive screening tool for SSc patients with signs and symptoms of PAH.

The pathogenic mechanisms of experimental PAH largely mirror what described in SSc vascular defects [17, 19-22], and on these bases, we searched for IL-32 expression in the skin samples of our SSc patients. Finally, we correlated the number of IL-32+ cells in the affected skin with the modified Rodnan skin score (mRSS), a surrogate for disease activity, severity and mortality in patients with dcSSc [37].

\section{Materials and methods}

\section{Patients and controls}

Eighteen SSc patients with WHO group 1 PAH [6], consecutively selected during the diagnostic RHC, and 21 patients with SSc [38] without PAH, selected among those patients consecutively admitted in our outpatient clinics, who underwent sPAP evaluation, showing a normal sPAP associated with no sign or symptom referred to heart involvement, in the context of their routinely clinical assessment, were enrolled for this cross-sectional study. All patients fulfilled the 2013 classification criteria for SSc [39]. The diagnosis of PAH was confirmed according to the European guidelines [14]. Fifteen patients with $\mathrm{PAH}$ and $14 \mathrm{HCs}$ were also evaluated as controls. For this study, sera of the SSc-PAH patients and sera of iPAH patients, collected at the time of diagnostic RHC, were matched with the sera of SSc patients without $\mathrm{PAH}$, and with the sera of HCs. Patients with infections, malignant diseases or other diseases, which could be possibly associated with increases of IL-32 sera levels, were excluded. SSc patients without PAH, needing prostanoids, calcium-channel blockers, phosphodiestererase- 
5 inhibitors and endothelin-1 receptor antagonists, were excluded from this study. Samples from SSc-PAH patients were collected before starting vasoactive therapies. All patients were evaluated by echocardiography, the initial non-invasive test for the screening of pulmonary hypertension [40, 41]. sPAP was estimated from peak tricuspid regurgitation jet velocities according to the equation: sPAP $=4(V) 2+\mathrm{RA}$ pressure, where $V$ is the peak velocity (in metres per second) of TRV, as previously performed [42].

\section{RHC}

RHC was performed via femoral venous access, with zero reference levelled at mid chest in the supine position. Parameters concerning pulmonary circulation were measured as follows: mean right atrium pressure, right ventricle pressure, pulmonary artery pressure and wedge pressure obtained after catheter balloon inflation at the end of expiration. Cardiac output was measured using the thermodilution technique, through a thermistortipped Swan-Ganz catheter, or the Fick technique in patients with severe tricuspid regurgitation. Pulmonary vascular resistance was calculated as (mPAP-PAWP)/ CO.

\section{Enzyme-linked immunosorbent assay}

Sera levels of IL-32 were determined by commercial human ELISA using Human IL-32 ELISA (R\&D, USA), according to the manufacturer's protocol. All experiments were performed in duplicate.

\section{Skin biopsies}

Full-thickness biopsy samples, $2 \times 0.5 \mathrm{~cm}$, isolated from excisional biopsy, were obtained from clinically involved skin of one third of the distal forearm of patients affected by SSc. Skin with a mRSS of $\geq 1$ was considered to be clinically involved [43]. Skin samples obtained from donors, matched for age and gender, undergoing a surgical treatment for trauma of arms, were used as controls. Both skin and blood samples derived from patients undergoing $\mathrm{RHC}$ were collected at the time of catheterization.

\section{Immunohistochemistry}

Each biopsy sample was fixed in 10\% buffered formalin, dehydrated in graded alcohol series, and embedded in paraffin. Skin sections (thickness $3 \mu \mathrm{m}$ ) were deparaffinised, treated with endogenous peroxidase blocking (Dako, USA) and then with Dako Protein block (Dako, USA) to block non-specific binding. After blocking, sections were incubated with anti-IL-32 antibody (AbCam, $\mathrm{UK}$ ). Visualisation of the primary antibodies was performed using EnVision Flex/HRP and DAB (diaminobenzidine) (both Dako, USA). No immunohistochemical staining was noted in negative control samples where the primary antibody was omitted. Sections were examined and photographed under light microscope (Olympus BX53). The number of positive cells was counted by two pathologists, blinded to tissue source and expressed as the mean of two observations for each sample. Results were reported as the median (range) of number of positive cells per microscopic field, considering the nonparametric distribution.

\section{Ethics committee approval}

The local ethics committee approved the study protocol (ASL1 Avezzano Sulmona L'Aquila, L'Aquila, Italy, protocol number \#1039, Università degli Studi di ROMA "La Sapienza" protocol number \#1011), which has been performed according to the Good Clinical Practice guidelines and the Declaration of Helsinki.

\section{Statistical analysis}

According to data distribution, results were presented as mean and standard deviation (SD) or median and interquartile range (IQR) as appropriate, and consequently, parametric or non-parametric $t$ tests were used to compare these variables. Spearman's correlation was used to correlate IL-32 with sPAP. Furthermore, the receiveroperating characteristic (ROC) curves were performed to evaluate the predictivity of IL-32 sera levels in identifying patients with PAH. The best cut-off for ROC curves was calculated by the Youden's index. Due to the relatively simple study design, few missing data were managed by exclusion of these from analyses. Statistical significance was expressed by a $p$ value $<0.05$. GraphPad Prism 5.0 software and Statistics Package for Social Sciences (SPSS version 17.0, SPSS Inc) were used for statistical analyses.

\section{Results}

Baseline characteristics of the study population

Eighteen SSc-PAH patients, 21 SSc patients without $\mathrm{PAH}, 15$ patients with iPAH and $14 \mathrm{HCs}$ were analysed. Demographic and clinical characteristics of our cohorts are summarised in Table 1.

The mean age of SSc-PAH patients was $69.8 \pm 8.0$ years; 16 patients were Caucasian female. The mean age of SSc patients without PAH was $60.5 \pm 9.3$ years; 18 patients were Caucasian female. The mean value of systolic pulmonary artery pressure (sPAP) estimated by Doppler echocardiography was $73.1 \pm 16.6$ in SSc-PAH patients, $23.3 \pm 4.4$ in SSc patients without PAH, and $68.7 \pm 20.5$ in patients with iPAH. Among the SSc-PAH patients, 13 patients showed the dcSSc form and 5 showed the lcSSc form, and among the SSc patients without $\mathrm{PAH}, 14 \mathrm{pa}-$ tients were classified as dcSSc and 7 as lcSSc. The mean value of mRSS of dcSSc-PAH patients was $16.8 \pm 2.4$; the 
Table 1 Baseline characteristics of the study population

\begin{tabular}{|c|c|c|c|c|}
\hline & SSC-PAH & SSC & Idiopathic PAH & Healthy control \\
\hline$N$ & 18 & 21 & 15 & 14 \\
\hline Men/woman ( $N$ of patients) & $2 / 16$ & $3 / 18$ & $5 / 10$ & $3 / 11$ \\
\hline Disease duration (years \pm SD & $21.1 \pm 7.6$ & $19.1 \pm 9.0$ & $20.0 \pm 10$ & \\
\hline Age (mean, years $\pm S D)$ & $69.8 \pm 8.0$ & $60.5 \pm 9.3$ & $62.5 \pm 14.6$ & $63.7 \pm 10.1$ \\
\hline IcSSc/dcSSc ( $N$ of patients) & $5 / 13$ & $7 / 14$ & & \\
\hline ACA/Scl70 ( $N$ of patients) & $5 / 13$ & $7 / 14$ & & \\
\hline Digital ulcers ( $N$ of patients) & 2 & 1 & & \\
\hline sPAP eco & $73.1 \pm 16.6$ & $23.3 \pm 4.4$ & $68.7 \pm 20.5$ & \\
\hline mPAP RHC & $43.0 \pm 10.6$ & & $49.9 \pm 21.0$ & \\
\hline mRSS in dcSSc (mean \pm SD) & $16.8 \pm 2.4$ & $10.6 \pm 7.1$ & & \\
\hline mRSS in IcSSc (mean \pm SD) & $3.6 \pm 2.5$ & $3.9 \pm 2.3$ & & \\
\hline Prostanoid & Not & Not & Not & Not \\
\hline Calcium-channel blockers & Not & Not & Not & Not \\
\hline Phosphodiestererase-5 inhibitors & Not & Not & Not & Not \\
\hline Endothelin-1 receptors antagonists & Not & Not & Not & Not \\
\hline Vasoactive therapies & Not & Not & Not & Not \\
\hline
\end{tabular}

ACA anti-centromere antibodies, $d c S S c$ diffuse cutaneous SSc, IcSSc limited cutaneous SSc, mPAP RHC mean pulmonary artery pressure measured by RHC, mRSS modified Rodnan skin score, $N$ number, $P A H$ Pulmonary arterial hypertension, $R H C$ right heart catheterization, $S D$ standard deviation, $s P A P$ eco systolic pulmonary artery pressure measured by echocardiography, SSC systemic sclerosis

mean value of mRSS of dcSSc patients without PAH was $10.6 \pm 7.1$.

\section{IL-32 sera levels in patients with SSc}

Figure 1a shows that the IL-32 sera levels were significantly higher in SSc-PAH patients, when compared with SSc patients without PAH $[99.9 \mathrm{pg} / \mathrm{ml}$ (55.4185.6) in SSc-PAH patients vs $0 \mathrm{pg} / \mathrm{ml}(0-9.9)$ in SSc patients without PAH; $p<0.0001]$. Additionally, the IL32 sera levels in SSc-PAH patients were significantly higher when compared with patients affected by iPAH [99.9 pg/ml (55.4-185.6) in SSc-PAH patients vs 62.1 $\mathrm{pg} / \mathrm{ml}(0-197.8)$ in patients with iPAH; $p=0.03]$. As reported in Fig. 1b, we did not found any significant difference in IL-32 sera levels when stratifying the patients according to disease subsets $[118.1 \mathrm{pg} / \mathrm{ml}$ (74.3-147.5) in lcSSc-PAH patients vs $91.6 \mathrm{pg} / \mathrm{ml}$ (55.4-185.6) in dcSSc-PAH patients, $p=0.4 ; 0 \mathrm{pg} / \mathrm{ml}$ $(0-7.2)$ in lcSSc patients without PAH vs $3.1 \mathrm{pg} / \mathrm{ml}(0-$ 9.9) in dcSSc patients without PAH, $p=0.3$ ].
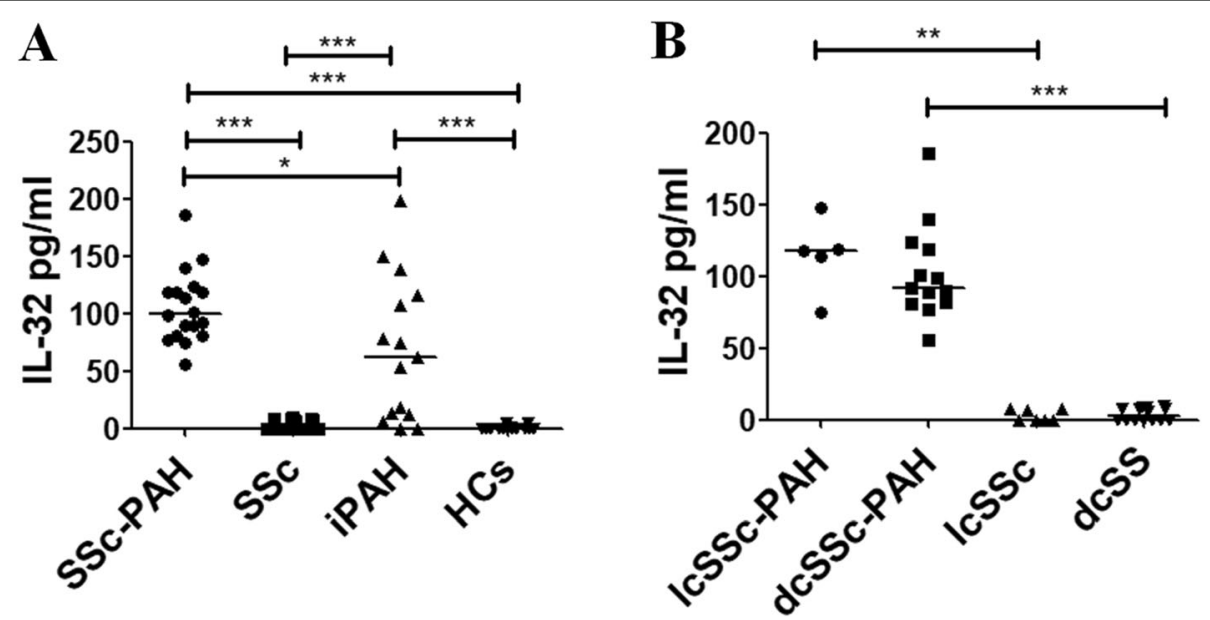

Fig. $1 \mathrm{IL}-32$ sera levels. a ELISA assays. In SSc-PAH patients, IL-32 sera levels are significantly higher when compared with SSC patients without PAH $\left({ }^{*} p=0.03 ;{ }^{* * *} p \leq 0.0001\right)$. b ELISA assays stratifying the SSC patients according to disease subset. No difference in IL-32 sera levels is assessed, stratifying the patients in limited cutaneous (IcSSc) subset and diffuse cutaneous (dcSSc) subset. Independent of the diseases subset, in SSc-PAH patients, IL-32 sera levels are significantly increased when compared to SSC patients without PAH $\left.{ }^{* *} p=0.002 ;{ }^{* * *} p<0.001\right)$ 
Sensitivity and specificity of IL-32 as biomarker to identify SSc-PAH patients

The area under the ROC curve resulted to be 0.950 (95\% CI 0.889-1.000, $p<0.0001)$ for IL-32 sera levels. By analysis of the ROC curve, we assessed that the best cutoff for IL-32 sera levels was $11.12 \mathrm{pg} / \mathrm{ml}$, to predict patients with $\mathrm{PAH}$, providing a sensitivity of $90 \%$ and a specificity of 100\% (Fig. 2).

\section{Correlations between IL-32 sera levels and MPAP evaluated by RHC in SSc patients}

Figure 3a shows a positive correlation between IL-32 levels obtained from SSc patients undergoing RHC, to confirm PAH, and their mPAP measures [Spearman $r=$ 0.37 (CI -0.01 to 0.66 ), $p=0.02$; linear regression $r^{2}=$ $0.13, p=0.02]$.

\section{Correlations between IL-32 sera levels and SPAP} evaluated by Doppler echocardiography in SSC patients Figure $3 \mathrm{~b}$ shows a positive correlation between IL-32 sera levels of SSc patients and SPAP measures [Spearman $r=0.68$ (CI 0.46-0.83), $p<0.0001$; linear regression $\left.r^{2}=0.7, p<0.0001\right]$.

\section{IL-32-positive cells in the skin of patients with SSc}

Figure 4 shows that IL-32 was expressed in keratinocytes, vascular cells and fibroblasts present in the derma. The number of IL-32+ cells was significantly increased in skin derived from SSc patients, when compared with HCs-skin [number of IL-32+ cells in SSc skin 55 (16152) vs number of IL-32+ cells in HCs skin 19.5 (10-

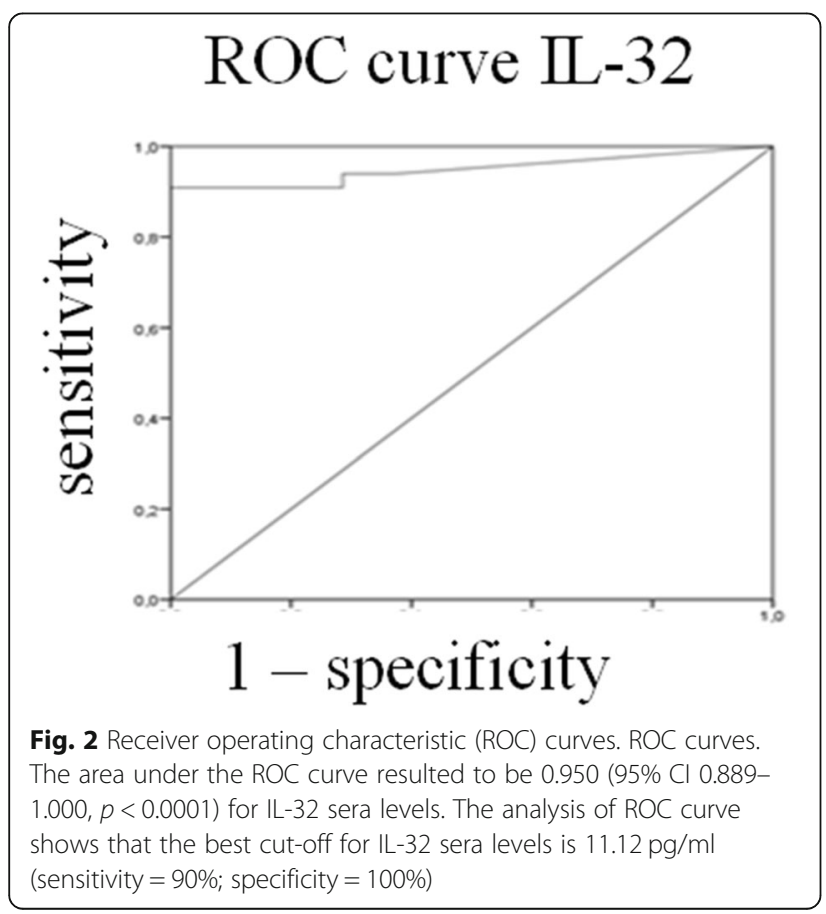

50); $p=0.0001]$. Among SSc patients, the IL-32+ cells were significantly increased in the subset of patients with $\mathrm{PAH}$ [number of IL-32+ cells in skin of SSc-PAH patients 110 (55-152) vs number of IL-32+ cells in skin of SSc patients 30 (16-60); $p<0.0001]$.

\section{Correlations between IL-32+ cells in the skin of dcSSc patients and $\mathrm{mRSS}$}

The number of IL-32+ cells in the skin of dcSSc patients directly correlated with values of mRSS (Fig. 5) [Spearman $r=0.42$ (CI 0.04-0.70), $p=0.02$; linear regression $\left.r^{2}=0.12, p=0.02\right]$.

\section{Discussion}

Our study suggests that IL-32, already identified in the lung of iPAH patients [25], may be considered a potential biomarker to identify SSc patients with WHO group $1 \mathrm{PAH}$. We enrolled 21 SSc-PAH patients, 13 showing the diffuse form and 5 the limited form of the disease. Although, it has been generally accepted that PAH is more common in lcSSc $[7,44,45]$, recent evidence failed to confirm these previous data, showing that $\mathrm{PAH}$ may also affect dcSSc patients at least as frequently as the limited form [46, 47].

We observed that IL-32 sera levels were higher in patients with $\mathrm{PAH}$; on the contrary, those levels were quite undetectable in SSc patients without $\mathrm{PAH}$ and $\mathrm{HCs}$, confirming the relevance of this cytokine in highlighting the presence of WHO group $1 \mathrm{PAH}$. It has been reported that IL-32 may play a key role in the vascular alterations occurring during $\mathrm{iPAH}$ and showing a proinflammatory effect in several inflammatory and autoimmune diseases [25, 33-35]. In fact, IL-32 has been described in the abnormal ECs, populating the plexiform lesions in the lungs from iPAH patients [25], and its production seems to promote the leukocyte recruitment via the production of pro-inflammatory cytokines, such as tumour necrosis factor- $\alpha$ (TNF- $\alpha$ ), IL-1 $\beta$, IL- 6 and IL-8 [27], all contributing to EC injury [24, 25, 31]. Furthermore, IL-32 may play an additional role, modulating activation and proliferation of ECs during the angiogenesis [25], although conflicting results are present in literature [48]. IL-32 may modulate the VEGF expression during cancer, promoting the pro-angiogenic program $[25,49]$, while in human bronchial epithelial cells, IL-32 appears to suppress the pro-angiogenic signals [48]. In our setting, the increase of IL-32 levels, observed only in the patients with $\mathrm{PAH}$, should be referred to the specific EC damage, associated with PAH, more than a disturbance of the immune-homeostasis, as reported for other autoimmune diseases [32, 33]. Although it is still unknown what isoform is associated with the organisation of plexiform lesions, during iPAH, one study suggested that IL-32 $\gamma$ may be the main isoform, involved in the 

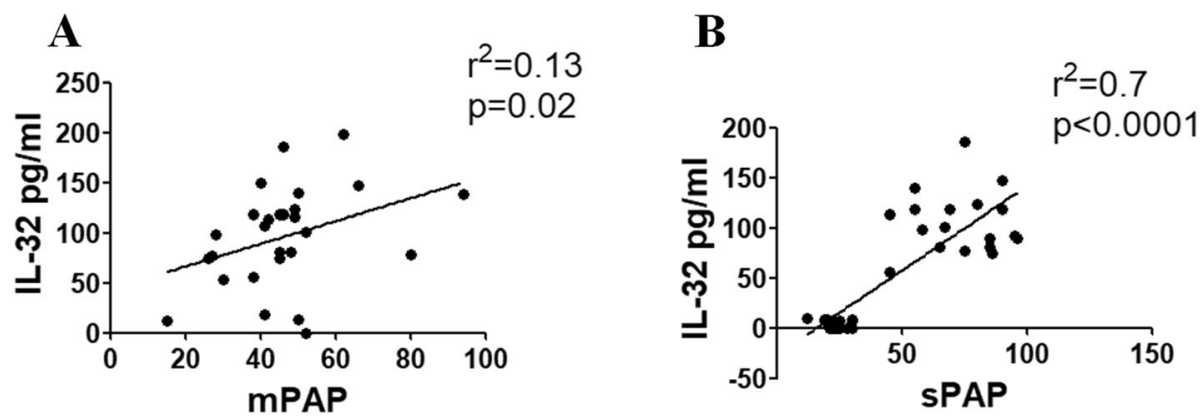

Fig. 3 Correlations between IL-32 sera levels and both mPAP and SPAP. a The correlation analysis of IL-32 sera levels and mPAP shows that the IL-32 sera levels of patients with SSC correlate with MPAP measures $\left(r^{2}=0.13 ; p=0.02\right)$. $\mathbf{b}$ The correlation analysis of IL-32 sera levels and sPAP shows that the IL-32 sera levels of patients with SSc correlate with SPAP measures $\left(r^{2}=0.7 ; p<0.0001\right)$

angiogenic process [25]. Nine different IL-32 isoforms have been identified [26], and among them, IL-32 $\alpha$, IL$32 \beta$ and IL-32 $\gamma$ are the most representative forms [26]. In this study, mirroring what was already done in others' papers measuring the levels of IL-32 as biomarker of diseases, we used ELISA kit to be able to recognise the three main isoforms ( $\alpha, \beta$ and $\gamma$ ), as reported by others $[34,50,51]$. Considering that the main goal of our work was to assess the possible use of IL-32 as a new and relevant biomarker to discriminate those SSc patients at higher risk of PAH, we did not analysed the specific role of any isoform. Surely, further studies are needed to establish the pathogenic role of each isoform in SSc patients developing PAH.

At present, no specific biomarker for $\mathrm{PAH}$ has been identified so far, although a wide variety of molecules have been explored [14], all of them lacking a significant specificity to identify patients to be referred to cardiologists for performing RHC and/or to follow up patients with already confirmed PAH. In our study, we identified the specific cut-off (IL-32 sera levels of $11.12 \mathrm{pg} / \mathrm{ml}$, sensitivity $=90 \%$, specificity $=100 \%$ ), which is able to

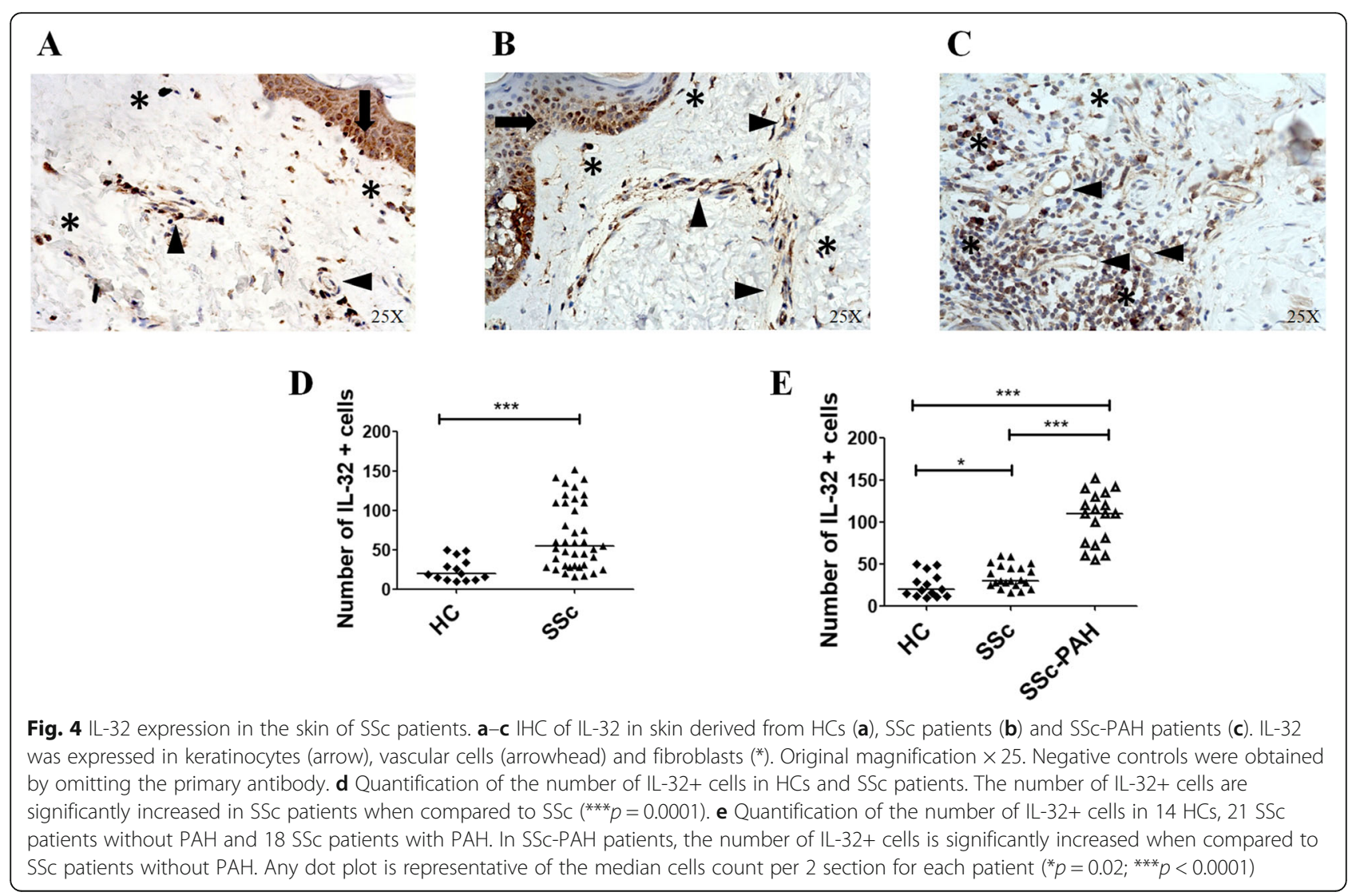




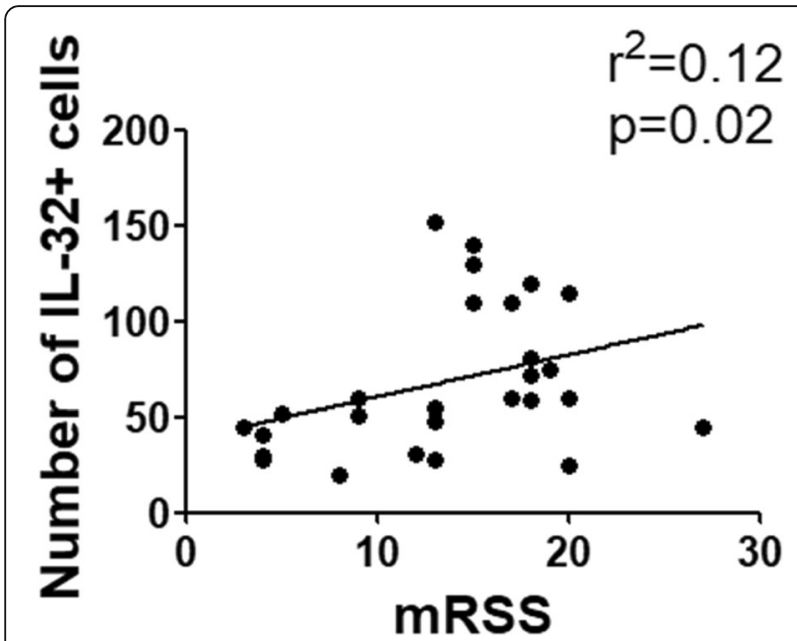

Fig. 5 Correlations between the number of IL-32+ cells and mRSS. The correlation analysis of the number of $\mathrm{IL}-32+$ cells, in the skin of dcSSc patients, and mRSS shows that the number of IL-32+ cells correlates with $\operatorname{mRSS}\left(r^{2}=0.12, p=0.02\right)$

discriminate SSc patients at higher risk of WHO group 1 $\mathrm{PAH}$. Although this study retrospectively assessed a relatively low number of patients, the strong sensitivity and specificity observed in our work suggest that IL-32 sera levels may emerge as a new specific biomarker, helpful for an accurate screening of SSc patients with suspected WHO group $1 \mathrm{PAH}$, being our results a proof-ofconcept to design further and powered studies to confirm and validate this result.

Of note, the IL-32 sera levels significantly correlated with the mPAP observed during RHC, in both iPAH and PAH-SSc patients. These results confirmed on one the hand the possibility that IL-32 may be a helpful biomarker in PAH patients and, on the other hand, its possible pathogenic role [25]. Furthermore, our results showed that the IL-32 sera levels significantly correlated with the sPAP evaluated with echocardiography, which is a non-invasive and feasible assessment of suspected $\mathrm{PAH}$ according to current guidelines [14, 52]. In fact, sPAP, evaluated by echocardiography, correlates with RHC. In this context, the need for biomarkers identifying the patients' profile at the highest risk for a poor outcome has become of crucial interest in autoimmune diseases [53, 54], and the correlation between IL-32 and both sPAP and mPAP could offer a new promising screening tool to be readily integrated in clinical practice. Furthermore, a serum determination could overcome the limitations of echocardiography, such as operator expertise, machine quality and patient acoustic window [55], suggesting the possible usefulness of an integrated approach.

Additionally, we assessed the expression of IL-32 in the skin of SSc patients. Our results showed that the number of IL-32+ cells was significantly increased in the skin of SSc patients, when compared with HC skin. IL32 was expressed in keratinocytes, vascular cells and fibroblast cells present in the derma. It has been reported that IL-32 may be produced by epithelial cells, fibroblasts keratinocytes and inflammatory cells, after stimulation with pro-inflammatory cytokines, including interferon- $\gamma$ and TNF- $\alpha$ [56], and all these cells are have been frequently found to be involved in SSc pathogenesis [57-60]. Furthermore, higher expression of IL-32 has been reported in human epidermal keratinocytes of atopic dermatitis, correlating with the severity of the diseases [61]. Interestingly, different from the relatively poor IL-32+ cells observed in the skin of patients without PAH, the SSc skin of patients with PAH showed a very rich IL-32+ cells, strongly confirming the very close association between IL-32 production and vascular complications leading to $\mathrm{PAH}$.

In this study, we showed a correlation between the number of IL-32+ cells and the mRSS of dcSSc patients. It is well known that the mRSS is the main measure of outcome in dcSSc with less than 5 years from the onset of the first symptom different from Raynaud's phenomenon. Thus, any biomarker, able to correlate with mRSS, may be considered as a surrogate outcome measure for severity and mortality in patients with dcSSc [37, 62, 63].

Although our study shows promising results, we are well aware about some limitations to generalise these results, including the single-centre retrospective design and the relatively small sample size, thus suggesting the need of further confirmatory studies.

\section{Conclusions}

In conclusion, our study suggests that higher IL-32 sera levels may be a useful biomarker for screening patients with WHO group $1 \mathrm{PAH}$, before invasive assessments. Despite future multi-centre, longitudinal studies are needed, on a larger cohort of patients, our preliminary results support the concept that IL-32 sera levels may contribute to an earlier detection of SSc patients to be referred to cardiologist for cardiac assessment, and ultimately improving the outcome, being the early diagnosis of PAH crucial for initiating the proper treatment.

\section{Abbreviations}

PAH: Pulmonary arterial hypertension; iPAH: Idiopathic PAH; SSc: Systemic sclerosis; dcSSc: Diffuse cutaneous SSc; IcSSc: Limited cutaneous SSc;

IL: Interleukin; ELISA: Enzyme-linked immunosorbent assay; HCs: Healthy controls; mRSS: Modified Rodnan skin score; NK cells: Natural killer cells; ROC: Receiver operating characteristic; BNP: B-type natriuretic peptide; NTproBNP: N-Terminal proBNP; EC: Endothelial cells; SPAP: Systolic pulmonary artery pressure; mPAP: Mean pulmonary artery pressure; TNF-a: Tumour necrosis factor-a

Acknowledgements

The authors thank Mrs. Federica Sensini for her technical assistance. 


\section{Authors' contributions}

PDB: study conception and design, data interpretation, literature search, figure creation, writing, paper revision and acceptance; GG study conception and design, acquisition of data, data interpretation, literature search, figure creation, writing, paper revision and acceptance; GM, PR, OB, NP, NG, RB, VR, CDV, GR, VL and FC acquisition of data, data interpretation, literature search, writing, paper revision and acceptance; PC and RG study conception and design, acquisition of data, data interpretation, writing, paper revision and acceptance. All authors gave final approval for submitting the manuscript for review and agree to be accountable for all aspects of the work.

\section{Funding}

No funding.

\section{Availability of data and materials}

Relevant files of this work will be shared on reasonable request.

\section{Ethics approval and consent to participate}

The experiments comply with the current Ethical standard laws of Italy. All patients gave fully informed written consent approved by the institutional ethics committee.

\section{Consent for publication}

Not applicable.

\section{Competing interests}

The authors declare that they have no competing interests.

\section{Author details}

${ }^{1}$ Clinical Pathology Unit, Department of Biotechnological and Applied Clinical Sciences, University of L'Aquila, L'Aquila, Italy. ${ }^{2}$ Rheumatology Section, Department of Internal Medicine, University of Palermo, Palermo, Italy. ${ }^{3}$ Department of Cardiovascular and Respiratory Sciences, Sapienza University of Rome, Rome, Italy. ${ }^{4}$ Division of Rheumatology, Department of Biotechnological and Applied Clinical Sciences, University of L'Aquila, L'Aquila, Italy. ${ }^{5}$ Department of Internal Medicine and Medical Specialities, Sapienza University of Rome, Rome, Italy. ${ }^{6}$ Secondary Hypertension Department with Pulmonary Hypertension Center, State Institute National Scientific Center "MD Strazhesko Institute of Cardiology" of Ukrainian National Academy of Medical Science, Kyiv, Ukraine. 'Rheumatology Section, Department of Clinical and Experimental Medicine, University of Campania "Luigi Vanvitelli", Naples, Italy.

\section{Received: 14 February 2020 Accepted: 13 May 2020} Published online: 01 June 2020

\section{References}

1. Denton CP, Khanna D. Systemic sclerosis. Lancet. 2017;399(10103):1685-99.

2. Di Cesare E, Battisti S, Di Sibio A, et al. Early assessment of sub-clinical cardiac involvement in systemic sclerosis (SSC) using delayed enhancement cardiac magnetic resonance (CE-MRI). Eur J Radiol. 2013;82(6):e268-73.

3. Matucci-Cerinic M, Giacomelli R, Pignone A, Cagnoni ML, Generini S, Casale $R$, et al. Nerve growth factor and neuropeptides circulating levels in systemic sclerosis (scleroderma). Ann Rheum Dis. 2001;60(5):487-94.

4. Cipriani P, Marrelli A, Liakouli V, Di Benedetto P, Giacomelli R. Cellular players in angiogenesis during the course of systemic sclerosis. Autoimmun Rev. 2011;10(10):641-6.

5. Giacomelli R, Di Cesare E, Cipriani P, Ruscitti P, Di Sibio A, Liakouli V, et al. Pharmacological stress, rest perfusion and delayed enhancement cardiac magnetic resonance identifies very early cardiac involvement in systemic sclerosis patients of recent onset. Int J Rheum Dis. 2017;20(9):1247-60.

6. Simonneau G, Montani D, Celermajer DS, Denton CP, Gatzoulis MA, Krowka M. Haemodynamic definitions and updated clinical classification of pulmonary hypertension. Eur Respir J. 2019;53(1):1801913.

7. Walker UA, Tyndall A, Czirják L, Denton C, Farge-Bancel D, Kowal-Bielecka O, et al. Clinical risk assessment of organ manifestations in systemic sclerosis: a report from the EULAR Scleroderma Trials And Research group database. Ann Rheum Dis. 2007:66(6):754-63.

8. Kawut SM, Taichman DB, Archer-Chicko CL, Palevsky HI, Kimmel SE. Hemodynamics and survival in patients with pulmonary arterial hypertension related to systemic sclerosis. Chest. 2003;123(2):344-50.
9. Simpson CE, Damico RL, Hummers L, Khair RM, Kolb TM, Hassoun PM, et al. Serum uric acid as a marker of disease risk, severity, and survival in systemic sclerosis-related pulmonary arterial hypertension. Pulm Circ. 2019;9(3): 2045894019859477.

10. Chaisson NF, Hassoun PM. Systemic sclerosis-associated pulmonary arterial hypertension. Chest. 2013;144(4):1346-56.

11. Chung L, Domsic RT, Lingala B, Alkassab F, Bolster M, Csuka ME, et al. Survival and predictors of mortality in systemic sclerosis-associated pulmonary arterial hypertension: outcomes from the pulmonary hypertension assessment and recognition of outcomes in scleroderma registry. Arthritis Care Res (Hoboken). 2014;66(3):489-95.

12. Hao Y, Thakkar V, Stevens W, Morrisroe K, Prior D, Rabusa C, et al. A comparison of the predictive accuracy of three screening models for pulmonary arterial hypertension in systemic sclerosis. Arthritis Res Ther. 2015;17(1):7

13. Giacomelli R, Liakouli V, Berardicurti O, Ruscitti P, Di Benedetto P, Carubbi F, et al. Interstitial lung disease in systemic sclerosis: current and future treatment. Rheumatol Int. 2017;37(6):853-63.

14. Galiè N, Humbert M, Vachiery JL, Gibbs S, Lang I, Torbicki A, et al. 2015 ESC/ ERS guidelines for the diagnosis and treatment of pulmonary hypertension: The Joint Task Force for the Diagnosis and Treatment of Pulmonary Hypertension of the European Society of Cardiology (ESC) and the European Respiratory Society (ERS): endorsed by: Association for European Paediatric and Congenital Cardiology (AEPC), International Society for Heart and Lung Transplantation (ISHLT). Eur Heart J. 2016;37(1):67-119.

15. Warwick G, Thomas PS, Yates DH. Biomarkers in pulmonary hypertension. Eur Respir J. 2008;32(2):503-12.

16. McHugh NJ, Distler O, Giacomelli R, Riemekasten G. Non organ based laboratory markers in systemic sclerosis. Clin Exp Rheumatol. 2003;21(3 Suppl 29):S32-S8.

17. Cipriani P, Di Benedetto P, Ruscitti P, Campese AF, Liakouli V, Carubbi F, et al. Impaired endothelium-mesenchymal stem cells cross-talk in systemic sclerosis: a link between vascular and fibrotic features. Arthritis Res Ther. 2014;16(15):442.

18. Vaillancourt M, Ruffenach G, Meloche J, Bonnet S. Adaptation and remodelling of the pulmonary circulation in pulmonary hypertension. Can J Cardiol. 2015;31(4):407-15.

19. Di Benedetto P, Ruscitti P, Liakouli V, Del Galdo F, Giacomelli R, Cipriani P. Linking myofibroblast generation and microvascular alteration: the role of CD248 from pathogenesis to therapeutic target. Mol Med Rep. 2019;20(2):1488-98.

20. Di Benedetto P, Liakouli V, Ruscitti P, Berardicurti O, Carubbi F, Panzera N. Blocking CD248 molecules in perivascular stromal cells of patients with systemic sclerosis strongly inhibits their differentiation toward myofibroblasts and proliferation: a new potential target for antifibrotic therapy. Arthritis Res Ther. 2018;20(1):223.

21. Cipriani P, Di Benedetto P, Ruscitti P, Capece D, Zazzeroni F, Liakouli V, et al. The endothelial-Mesenchymal transition in SSc is induced by the synergistic effect of ET-1 and TGF- $\beta$ and may be blocked by macitentan, a new dual ET-1 receptor antagonist. J Rheumatol. 2015:42(10):1808-16.

22. Cipriani P, Marrelli A, Di Benedetto P, Liakouli V, Carubbi F, Ruscitti P, et al. Scleroderma Mesenchymal stem cells display a different phenotype from healthy controls; implications for regenerative medicine. Angiogenesis. 2013;16(3):595-607.

23. Dinarello CA, Kim SH. IL-32, a novel cytokine with a possible role in disease. Ann Rheum Dis. 2006;65(Suppl 3):iii61-4.

24. Nold-Petry CA, Nold MF, Zepp JA, Kim SH, Voelkel NF, Dinarello CA. IL-32dependent effects of IL-1b on endothelial cell functions. Proc Natl Acad Sci U S A. 2009:106(10):3883-8.

25. Nold-Petry CA, Rudloff I, Baumer Y, Ruvo M, Marasco D, Botti P, et al. IL-32 promotes angiogenesis. J Immunol. 2014;192:589-602.

26. Choi JD, Bae SY, Hong JW, Azam T, Dinarello CA, Her H, et al. Identification of the most active interleukin-32 isoform. Immunology. 2009;126(4):535-42.

27. Heinhuis B, Netea MG, van den Berg WB, Dinarello CA, Joosten LA. Interleukin-32: a predominantly intracellular proinflammatory mediator that controls cell activation and cell death. Cytokine. 2012;60(2):321-7.

28. Manetti M, Ibba-Manneschi L, Liakouli V, Serena Guiducci, Anna Franca Milia, Gemma Benelli et al. the IL1-like cytokine IL33 and its receptor ST2 are abnormally expressed in the affected skin and visceral organs of patients with systemic sclerosis. Ann Rheum Dis 2010;69(3):598-605 
29. Ciccia F, Alessandro R, Rizzo A, Raimondo S, Giardina A, Raiata F, et al. IL-33 is overexpressed in the inflamed arteries of patients with giant cell arteritis. Ann Rheum Dis. 2013;72:258-64.

30. Ciccia F, Rizzo A, Ferrante A, Guggino G, Croci S, Cavazza A, et al. New insights into the pathogenesis of giant cell arteritis. Autoimmun Rev. 2017; 16(7):675-83.

31. Ciccia F, Alessandro R, Rizzo A, Principe S, Raiata F, Cavazza A, et al. Expression of interleukin-32 in the inflamed arteries of patients with giant cell arteritis. Arthritis Rheum. 2001;63(7):2097-104.

32. Ciccia F, Rizzo A, Accardo-Palumbo A, Giardina A, Bombardieri M, Guggino G, et al. Increased expression of interleukin-32 in the inflamed ileum of Ankylosing spondylitis patients. Rheumatology (Oxford). 2012;51(11):1966-72.

33. Alsaleh G, Sparsa L, Chatelus E, Ehlinger M, Gottenberg JE, Wachsmann D, et al. Innate immunity triggers IL-32 expression by fibroblast-like synoviocytes in rheumatoid arthritis. Arthritis Res Ther. 2010;12(4):R135.

34. Ha YJ, Park JS, Kang MI, Lee SK, Park JB, Sang-Won Lee SW. Increased serum interleukin-32 levels in patients with Behçet's disease. Int J Rheum Dis. 2018; 21(12):2167-74.

35. Kitayama N, Otsuka A, Nonomura Y, Nakashima C, Honda T, Kabashima K. Decrease in serum IL-32 level in patients with atopic dermatitis after cyclosporine treatment. J Eur Acad Dermatol Venereol. 2017;31(10):e449-50.

36. Kwon OC, Ghang B, Lee EJ, Hong S, Lee CK, Yoo B, Kim S, Kim YG. Interleukin-32y: possible association with the activity and development of nephritis in patients with systemic lupus erythematosus. Int J Rheum Dis. 2019;22(7):1305-11.

37. Khanna D, Furst DE, Clements PJ, Allanore Y, Baron M, Czirjak L, et al. Standardization of the modified Rodnan skin score for use in clinical trials of systemic sclerosis. J Scleroderma Relat Disord. 2017;2(1):11-8.

38. LeRoy EC, Black C, Fleischmajer R, Jablonska S, Krieg T, Medsger TA, et al. Scleroderma (systemic sclerosis): classification, subsets and pathogenesis. J Rheumatol. 1988;15(2):202-5

39. van den Hoogen F, Khanna D, Fransen J, Johnson SR, Baron M, Tyndall A, et al. 2013 classification criteria for systemic sclerosis: an American college of rheumatology/European league against rheumatism collaborative initiative. Ann Rheum Dis. 2013;65(11):2737-47.

40. Fisher MR, Forfia PR, Chamera E, Housten-Harris T, Champion HC, Girgis RE, et al. Accuracy of Doppler echocardiography in the hemodynamic assessment of pulmonary hypertension. Am J Respir Crit Care Med. 2009; 179(7):615-21.

41. Barst RJ, McGoon M, Torbicki A, Sitbon O, Krowka MJ, Olschewski H, et al. Diagnosis and differential assessment of pulmonary arterial hypertension. Rev J Am Coll Cardiol. 2004;43(12 Suppl S):40S-7S.

42. Nagel C, Henn P, Ehlken N, D'Andrea A, Blank N, Bossone E, Böttger A, Fiehn C, Fischer C, Lorenz HM, Stöckl F, Grünig E, Egenlauf B. Stress Doppler echocardiography for early detection of systemic sclerosis-associated pulmonary arterial hypertension. Clin Trial Arthritis Res Ther. 2015;17(1):165

43. Kahaleh MB, Sultany GL, Smith EA, Huffstutter JE, Loadholt CB, Le Roy EC. A modified scleroderma skin scoring method. Clin Exp Rheumatol. 1986;4(4):367-9.

44. García-Hernández FJ, Castillo-Palma MJ, Tolosa-Vilella C, Guillén-del Castillo A, Rubio-Rivas M, Freire $M$, et al. Pulmonary hypertension in Spanish patients with systemic sclerosis. Data from the RESCLE registry. Clin Rheumatol. 2019;38(4):1117-24.

45. Iudici M, Codullo V, Giuggioli D, Riccieri V, Cuomo G, Breda S, et al. Pulmonary hypertension in systemic sclerosis: prevalence, incidence and predictive factors in a large multicentric Italian cohort. Clin Exp Rheumatol. 2013;31(2 Suppl 76):31-6.

46. Denton $\mathrm{CP}$, Hachulla E. Risk factors associated with pulmonary arterial hypertension in patients with systemic sclerosis and implications for screening. Eur Respir Rev. 2011;20(122):270-6.

47. Hunzelmann N, Genth E, Krieg T, Lehmacher W, Melchers I, Meurer M, Moinzadeh $P$, et al. The registry of the German Network for Systemic Scleroderma: frequency of disease subsets and patterns of organ involvement. Rheumatology (Oxford). 2008;47(8):1185-92

48. Meyer N, Christoph J, Makrinioti H, Indermitte P, Rhyner C, Soyka M, et al. Inhibition of angiogenesis by IL-32: possible role in asthma. J Allergy Clin Immunol. 2012;129(4):964-73.e7.

49. Sloot YJE, Smit JW, Joosten LAB, Netea-Maier RT. Insights into the role of IL32 in cancer. Semin Immunol. 2018;38:24-32.

50. Fadaei R, Bagheri N, Heidarian E, Ali Nouri, Zahra Hesari, Nariman Moradi et al. Serum levels of IL-32 in patients with type 2 diabetes mellitus and its relationship with TNF-a and IL-6. Cytokine 2020;125:154832.
51. Rafiei A, Mohammadjafari H, Ahifar A, Alipour A, Mirabi AM. The urinary and serum levels of IL-32 in children with febrile urinary tract infections. Future Sci OA. 2017;3(4):FSO242.

52. Greiner S, Jud A, Aurich M, Hess A, Hilbel T, Hard S, et al. Reliability of non invasive assessment of systolic pulmonary artery pressure by Doppler echocardiography compared to right heart catheterization: analysis in a large patient population. J Am Heart Assoc. 2014;3(4):e001103.

53. Giacomelli R, Afeltra A, Alunno A, Bartoloni-Bocci E, Berardicurti O, Bombardieri $\mathrm{M}$, et al. Guidelines for biomarkers in autoimmune rheumatic diseases-evidence based analysis. Autoimmun Rev. 2019;18(1):93-106.

54. Riccieri V, Vasile M, lannace N, Stefanantoni K, Sciarra I, Vizza CD, et al. Systemic sclerosis patients with and without pulmonary arterial hypertension: a nailfold capillaroscopy study. Rheumatology (Oxford). 2013; 52(8):1525-8.

55. Huang SJ, McLean AS. Appreciating the strengths and weaknesses of transthoracic echocardiography in hemodynamic assessments. Cardiol Res Pract. 2012;2012:894308.

56. Suga H, Sugaya M, Miyagaki T, Kawaguchi M, Fujita H, Asano Y, et al. The role of IL-32 in cutaneous T-cell lymphoma. J Invest Dermatol. 2014;134(5): 1428-35.

57. Cifone GM, Giacomelli R, Famularo G, Paolini R, Danese C, Napolitano T, et al. Natural killer activity and antibody-dependent cellular cytotoxicity in progressive systemic sclerosis. Clin Exp Immunol. 1990;80(3):360-5.

58. Giacomelli R, Cipriani P, Fulminis A, Barattelli G, Matucci-Cerinic M, D'Alò S, et al. Circulating gamma/delta T lymphocytes from systemic sclerosis (SSC) patients display a T helper (Th) 1 polarization. Clin Exp Immunol. 2001; 125(2):310-5.

59. Lescoat A, Lecureur $V$, Roussel M, Sunnaram BL, Ballerie A, Coiffier G, et al. CD16-positive circulating monocytes and fibrotic manifestations of systemic sclerosis. Clin Rheumatol. 2017;36(7):1649-54.

60. Klein M, Schmalzing M, Almanzar G, Benoit S, Hamm H, Tony HP, et al. Contribution of CD8+ T cells to inflammatory cytokine production in systemic sclerosis (SSC). Autoimmunity. 2016;49(8):532-46.

61. Meyer N, Zimmermann M, Bürgler S, Bassin C, Woehrl S, Moritz K, et al. IL-32 is expressed by human primary keratinocytes and modulates keratinocyte apoptosis in atopic dermatitis. J Allergy Clin Immunol. 2010;125(4):858-65.

62. Matsuda KM, Yoshizaki A, Kuzumi A, Fukasawa T, Ebata S, Miura S. Skin thickness score as a surrogate marker of organ involvements in systemic sclerosis: a retrospective observational study. Arthritis Res Ther. 2019;21(1): 129.

63. Dobrota R, Maurer B, Graf N, Jordan S, Mihai C, Kowal-Bielecka O, et al. Prediction of improvement in skin fibrosis in diffuse cutaneous systemic sclerosis: a EUSTAR analysis. Ann Rheum Dis. 2016;75(10):1743-8.

\section{Publisher's Note}

Springer Nature remains neutral with regard to jurisdictional claims in published maps and institutional affiliations.

Ready to submit your research? Choose BMC and benefit from:

- fast, convenient online submission

- thorough peer review by experienced researchers in your field

- rapid publication on acceptance

- support for research data, including large and complex data types

- gold Open Access which fosters wider collaboration and increased citations

- maximum visibility for your research: over $100 \mathrm{M}$ website views per year

At $\mathrm{BMC}$, research is always in progress.

Learn more biomedcentral.com/submission 